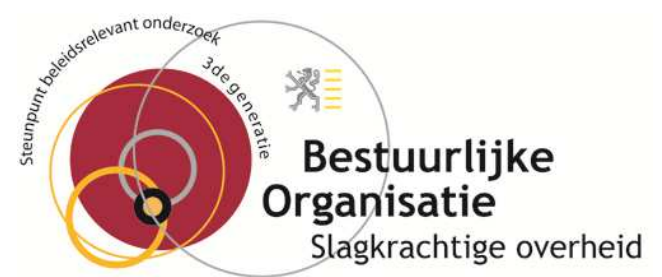

\title{
Strategic Choices regarding Talent Management in the Flemish Public Sector ${ }^{1}$
}

\author{
$>$ Working Paper
}

$>\quad$ Dorien Buttiens \& Annie Hondeghem

\footnotetext{
1 This text is based on research conducted within the frame of the Policy Research Centre on Governmental Organization - Decisive Governance (SBOV III - 2012-2015), funded by the Flemish government. The views expressed herein are those of the author(s) and not those of the Flemish government. This text is an extension of the paper presented at the EIASM Workshop on Talent Management - 7-8 oktober 2013 and at the conference of the Dutch HRM network in Leuven - 14-15 november 2013
} 



\section{Index}

1. Introduction 3

2. Theoretical background 5

> 2.1. Talent management within the contingency perspective 5

> 2.2. Talent management in a public sector context 9

> 2.3. Conceptualization of talent management 10

3. Methodology 14

$>$ 3.1. Survey 15

> 3.2. Semi-structured in-depth interviews 17

$\begin{array}{lll}\text { 4. } & \text { Results } & 18\end{array}$

> 4.1. A shared understanding of talent management in the Flemish government?

> 4.2. Approach to and design of talent management in the Flemish government

4.2.1. Development stage of the organizations' talent management policies $\quad 21$

4.2.2. Approach to Talent Management 23

$>$ 4.2.3. HR processes in the entities' talent management policies 25

$>$ 4.3. Influencing factors on talent management in the Flemish government

$>$ 4.3.1. Configuration of the organization (the organizational/administrative/cultural heritage) $\quad 28$

> 4.3.2. Product/market/technology dimension 31

$>$ 4.3.3. Social/cultural/legal dimension 33

$>$ 4.3.4. Dominant coalition 36

5. Conclusion 37

6. References 40 



\section{Introduction}

Recently, several authors have concluded that the research on talent management has entered a new stage in its 'maturing' process. Where Dries (2013) holds that talent management evolved from an embryonic state to a growing state and is quickly approaching the mature phase of a field of study, Thunissen, Boselie \& Fruytier (2013) state in their literature study that the research field has almost attained the stage of infancy 'with some progress towards adolescense'. The main conclusion of these authors, however, is that the field still lacks in empirical research while a managerialist and unitarist view on talent management is promoted in the prevailing academic literature. In addition, Thunissen, Boselie \& Fruytier (2013) acknowledge, from a pluralist point of view, that the approach to talent is not only determined by the management of an organization but also by other stakeholders such as employees, colleagues, peers and society (cfr. Bossuyt \& Dries, 2008). Furthermore, it is stated that, in the past decade, talent management research has mainly focused on (large) organizations in a for-profit context (Collings \& Mellahi, 2009; Thunissen, Boselie \& Fruytier, 2013). Therefore, Vaiman \& Collings (2013) rightly call for insights from different cultural and institutional contexts with regard to the meanings of talent and talent management.

The approaches to and conceptualizations of talent and talent management that are being put forth in academic literature today differ significantly from each-other (Lewis \& Heckman, 2006; Armstrong, 2006; Thunissen, Boselie \& Fruytier, 2013; Gallardo-Gallardo et al., 2013). Aside from these differences in approach and definition, talent management policies are often developed with different goals and HR processes in mind. As Vaiman \& Collings have rightly stressed 'organizations develop talent systems which reflect particular organizational objectives in the context of the strategic 
constraints which they face' (Vaiman \& Collings, 2013). This means that a contingency perspective is the most suitable option to theoretically incorporate the connection between an organiaation's corporate culture and business strategy and the talent management policy it is adopting. As Thunissen, Boselie \& Fuytier (2013) have indicated, mainstream literature on Talent management only rarely pays attention to the influence of such external environments, the so-called 'external fit' (next to the organizational, strategic and internal fit).

This research paper aims to negotiate the above-mentioned concerns by presenting an overall picture of the specific approaches, goals and HR processes of talent management in a public sector context. Specifically, we will present preliminary results of a number of in-depth semi-structured interviews that are being conducted with 19 HR-managers of entities within the Flemish government. These interviews focus on the external fit of the talent management policy (e.g. stakeholder interests, configuration of the organisation). In addition, we pay attention to the process of outlining the parties that are part of the dominant coalition. This dominant coalition is responsible for adjusting the HR-policy within the entities of the Flemish government and potentially integrates the viewpoint of stakeholders. We therefore apply the Contextually based Human Resource Theory (CBHRT) of Paauwe (2004) which tries to explain the choice for an HR policy by looking at several dimensions ${ }^{2}$ in the (institutional) environment of an organization and taking into account the influence of stakeholders. In doing so, the organization becomes embedded in its broader institutional environment.

\footnotetext{
${ }^{2}$ The dimensions that play a role in the CBHRT are the product/market/technology dimension, the social/cultural/legislative dimension and the organization configuration. 


\section{Theoretical background}

In the theoretical background, we will present the appearance of several talent management approaches and the dependency on contextual factors. In this regard, the Contextually based Human Resource Theory will be highlighted. Subsequently, we will situate talent management in a public sector context while cautioning for the use of too strict a dichotomy between private and public organizations. We will conclude this section by presenting five tensions that Dries (2013) distinguishes in the literature. These tensions can serve as a steppingstone in the process of elucidating the chosen approach and design of specific talent management policies, as the underlying beliefs and ideas are taken into account.

\section{> 2.1. Talent management within the contingency perspective}

When reading about talent management in academic literature, it is clear that different approaches to and conceptualizations of talent and talent management exist (Lewis \& Heckman, 2006; Armstrong, 2007; Thunissen, Boselie \& Fruytier, 2013; Gallardo-Gallardo et al., 2013). Dries (2013) even points out in her comparative review of the talent management literature that "the majority of publications on talent management do not offer a formal definition of their central concept, nor does a significant proportion of organizations that have a talent management system in place". In this matter, Vaiman \& Collings (2013) state that differences in approach and definition lead back to different takes on talent management (e.g. inclusive talent management vs exclusive talent management; emphasis on performance vs potential;...). The preference of an organization for a certain aspect of talent management can be placed within the contingency or best fit model (Garrow \& Hirsh, 2008). As stated in the introduction, 
Vaiman \& Collings (2013) stress the influence of organizational objectives and strategic constraints of an organization on the approach and development of talent management policies. In this regard, Thunissen, Boselie \& Fruytier (2013) note that the main focus of organizations is on the strategic $\mathrm{fit}^{3}$. As a consequence, both organizational ${ }^{4}$ and external $\mathrm{fit}^{5}$ are not included in the mainstream literature on talent management research.

Given that these aspects do play an important role, we have chosen to use the Contextually based Human Resource Theory (CBHRT) of Paauwe (2004) as a framework for this research paper ${ }^{6}$. The CBHRT is rooted in new institutionalism and focuses on the embeddedness of the organization in its broader institutional environment. In addition, the CBHRT also acknowledges the importance of balancing values. In other words, during the development process of an HR policy, the potentially differing values and goals of stakeholders need to be taken into account. The views of shareholders as well as those of interest groups and employees are thus integrated within the goals that are being put forward. Among the actors with a defining role within the policy development process, stakeholders of the organization take this place next to those of the shareholders. The CBHRT thus incorporates the strategic fit as well as the organizational and external fit.

\footnotetext{
${ }^{3}$ Boselie (2010) defines strategic fit as an alignment of the HR-practices with the organization's strategy

4 Boselie (2010) defines organizational fit as a fit between the HR strategy and other organizational systems (e.g. legal system, information and communication system,... )

5 Boselie (2010) defines institutional fit as the link between the HR strategy and the institutional environment of an organization.

${ }^{6}$ The CBHRT is one of the avenues for future research that is recommended by Thunissen et al. (2013 review)
} 


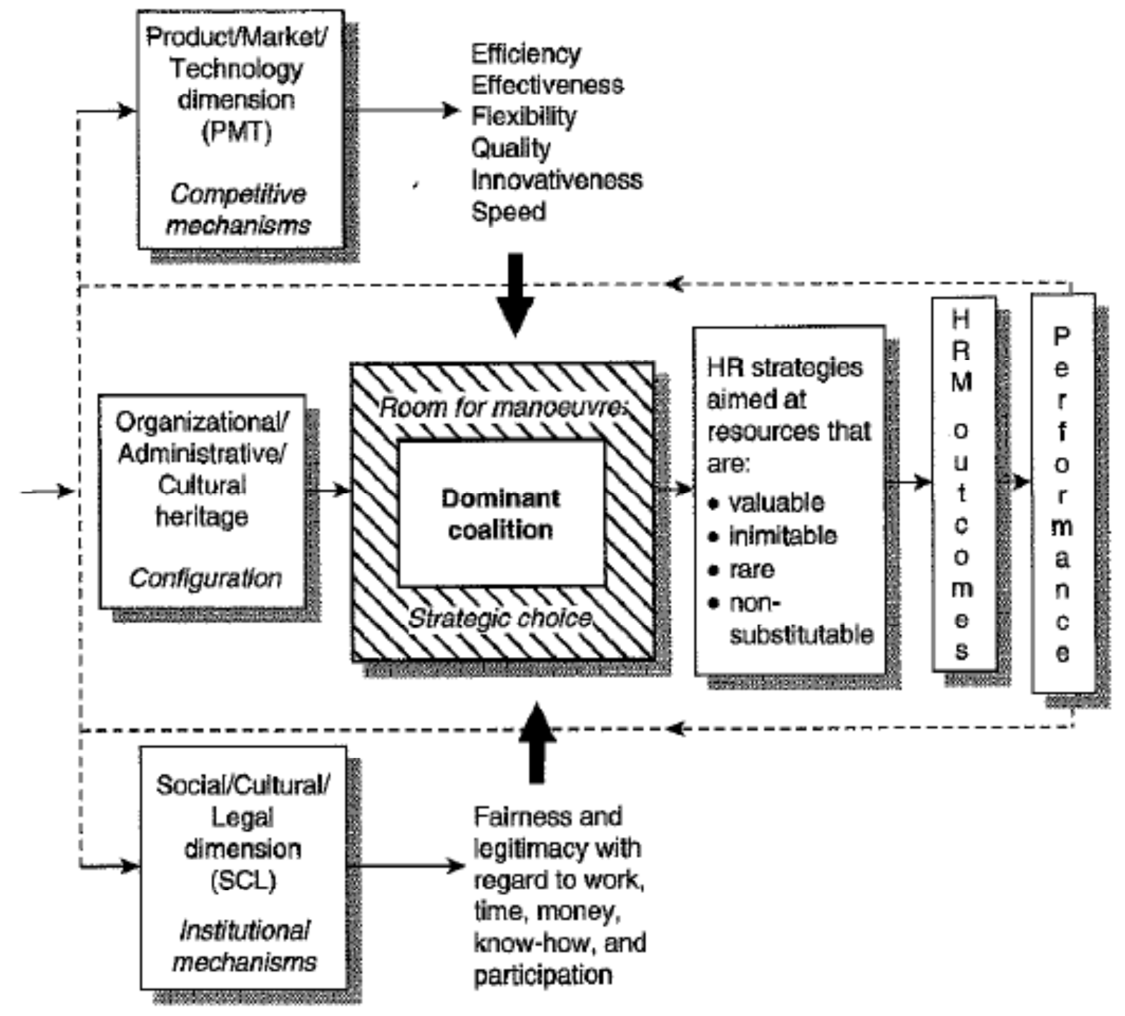

Source: Paauwe, 2004

The three dimensions that are put forward by Paauwe (2004) are the product/market/technology dimension (PMT-dimension), the social/cultural/legal dimension (SCL-dimension) and the organizational/administrative/cultural heritage (configuration of the organization). These dimensions have a considerable impact on the shape and structure of the HR-policy of an organization. The first dimension deals with the demands that arise from relevant product market combinations and 
the use of appropriate technology (Paauwe, 2004). These demands are expressed through criteria such as efficiency, effectiveness, flexibility, quality and innovativeness. In addition, organizations are also placed in a socio-political, cultural and legal context (the SCL-dimension). These values and norms (e.g. fairness and legitimacy) direct and correct the outcomes of different processes and trends within the PMT-dimension. The last dimension focuses on the configuration of the organization. Paauwe (2004) defines this dimension as 'the outcome of past choices of strategy in interaction with the way in which structuring issues were originally posed and the kind of organizational culture this had engendered'. Next to the above-mentioned dimensions, Paauwe (2004) also integrates the concept of a dominant coalition. This concepts adds a true actor perspective to the model. The relative weight of th enormas and values of these actors can now be taken into account when defining the degree of leeway that is left for the development of an HR policy. The actor perspective brings into view these parties that play a part in the development of the HR system of an organization. Next to the internal actors of an organization, stakeholders, such as trade unions, interests groups and customers have an important influence on the decision making regarding the final outlook of the HR system.

In other words, an organization that tries to incorporate different rationalities (economic and relational) into the design of its talent management policy does so from a vantage point that includes norms and values, ideology, its position on the labour market and the history of the organization ${ }^{7}$.

\footnotetext{
${ }^{7}$ As a consequence, a multi-dimensional view on performance is needed in which individual, organizational as well as societal goals are included. 


\section{> 2.2. Talent management in a public sector context}

"While the introduction of talent management may be a response to a changing business environment and signal a shift to a more proactive culture of employee development and performance management, it also needs to fit with other people management practices and support the core values and purpose of the organization" (Garrow \& Hirsh, 2008)

As Thunnissen, Boselie \& Fruytier (2013) noted, academic research concerning Talent Management can mainly be situated in 'multinational, private, and US-based organizations'. In addition, this research features a strong tendency towards a unitarist and managerialist orientation. This means that the importance of organizational effectiveness is central, while the individual and societal goals are often disregarded. As a consequence, the authors conclude that the prevalent theoretical models are unable to sufficiently render the differences and peculiarities of talent management in the public sector. Furthermore, it is clear that HR practices in a public sector context will have to take into account possibly incompatible values and goals since this reflects the characteristics of a public sector institution in which several stakeholders have to be accounted for.

While we do acknowledge that specific characteristics ${ }^{8}$ of a public sector organization can be distinguished, we also plead for caution in putting forward too strict a dichotomy between the profit and not-for-profit sector. At present, the public sector is under pressure to focus on organizational effectiveness and efficiency. In this respect, Bach (2000) states that, in the public sector, attention must be paid to changing priorities in favor of economic viability rather than social legitimacy. Specific tensions may arise in the process of implementing (some approaches to) talent management in

\footnotetext{
${ }^{8}$ The public sector context is characterized by numerous rules, prescriptions and norms and values which limit the flexibility to design a modern HR policy
} 
public sector organizations. These tensions are said to 'arise largely from well-embedded organizational approaches to equality and diversity' (Harris \& Foster, 2010).

We believe that the framework of the Contextually based Human Resource Theory allows one to incorporate the specific characteristics of public sector organizations while potential problems of using a strict dichotomy between private and public organizations are avoided. The influence of values and goals on the talent management policy of a public sector organization can be studied by using the above-mentioned dimensions of the Contextually Based Human Resource Theory.

\section{> 2.3. Conceptualization of talent management}

As mentioned throughout the previous section, the approaches to talent management seem to be an amalgam of different meanings and conceptualizations of talent and talent management (Thunissen et al., 2013; Gallardo-Gallardo et al., 2013). As stated above, contextual factors influence the design and approach an organization takes with regard to talent management. Making a start with the conceptualization of talent management, several authors have presented typologies that differentiate the 'types' of talent management that appear in practice (Dries, 2013; Gallardo-Gallardo et al., 2013). These typologies offer a steppingstone to determine the consequences of choosing a certain approach. Moreover, even the underlying ideology of an approach can be determined by uncovering these different approaches to talent management.

The typology of Dries (2013) is based on a literature review in six different strands ${ }^{9}$ of literature in which talent management is discussed. This literature review resulted in the identification of five tensions regarding the

${ }^{9}$ These six strands are: HRM, I/O psychology, educational psychology, vocational psychology, positive psychology, social psychology. 
operationalization of talent (inclusive vs. exclusive, object vs. subject, innate vs. acquired, input vs. output, transerfable vs context-dependent). An overview is provided in table 1. Each of these tensions can be linked to a key discussion point, the positions an organization can take regarding this tension, and the practical consequences of choosing a certain talent management policy. Dries (2013) further states that these tension points can be seen as a continuum on which organizations can assume a more or less extreme position (see figure 1 ). 





In the survey, talent management is operationalized on the basis of the tension between the inclusiveness or exclusiveness of the talent management policy. We will thus take a closer look at the defined inclusive vs. exclusive tension by Dries (2013). In future research phases, these five tensions can be used to analyse a talent management policy at entity-level. Such an analysis is, however, not part of the scope of the present paper.

\section{Tension between inclusive vs exclusive perspectives on talent}

Dries (2013) defines the key discussion point for this first tension as the estimated prevalence of talent in the (working) population. For the inclusive perspective, one starts from the premise that all employees are talented (but in a different way) while according to the exclusive perspective, some people are deemed to be more talented than others (within an organizational context). As a consequence, depending on the position an organization is taking on the inclusive-exclusive continuum, the talent management policy of an organization will be more or less aimed at a specific employee group in the organization.

Looking at the distinction between inclusive and exclusive talent management, the exclusive talent management approach can be situated in the prevailing managerialist/utilitarian model that mainly focuses on organizational performance and less so on individual and societal goals. Concentrating merely on key strategic positions or those groups of employees that occupy these strategic positions can be considered as a one dimensional focus on organizational goals. As such, this approach can be situated in the hard utilitarian HR approach as being much more shareholder oriented and less attentive to situational factors (Boselie, Brewster \& Paauwe, 2009). Since research on talent management is dominantly conducted in 'multinational, private, and US-based organizations', this 
could explain the preferred exclusive orientation of the organizations (Thunissen, Boselie \& Fruytier, 2013; Gallardo-Gallardo, 2013). However, Stahl et al. (2012), as well as Sparrow et al. (2011), found that organizations also combine both perspectives into 'a hybrid approach' (Thunissen, Boselie \& Fruytier, 2013).

Incorporation of an inclusivity-oriented talent management approach in the personnel policy of an organization however makes it possible to acquire a multidimensional view on performance (the individual and societal level as well as the economic goals of the organization). In this respect, Knies (2012) concludes that an organization acknowledges that everyone possesses strengths and competencies ('talents') that can be of value for the goals of the organization. So on the one hand, the organization strives to fulfill the wishes and needs of the individual while on the other, organizational success is being put forward. Hence, there is a balance between the different values.

In this paper, the main focus will be on the inclusive-exclusive continuum. Where possible, however, results of the survey and interviews will relate to the five tensions as proposed by Dries (2013).

\section{Methodology}

First, this paper will present the results of a survey in organizations of the Flemish government. The results of this research phase provide a blue-print of the design and approach to talent management in the entities of the Flemish government. Second, we present the preliminary results of in-depth interviews that are conducted in several of the surveyed entities. These interviews were conducted to deepen our understanding of the results of the survey and to explore the factors that influenced the introduction, the 
chosen approach to and finally their design of a talent management policy, as mentioned above. We subdivided these factors along the three dimensions and the concept of 'dominant coalition' of the Contextually based Human Resource Theory.

\section{$>$ 3.1. Survey}

The survey was aimed at the departments and agencies of the thirteen policy domains in the Flemish government. In total, we sent the survey to 60 organizations. The survey was addressed to the heads of the HR team ${ }^{10}$. This means that we sent the survey to one person in each organization. In this manner, we could determine which approach the organizations are taking regarding their (future) talent management policy. A limitation of this method is that we only get a view on the intentions of the entities regarding the talent management policy. The day-to-day implementation and the perceptions of employees regarding these practices is not part of this research phase. We are aware though that in practice the talent management policy can differ from what is said by the employees responsible for the HR policy. Nevertheless, this method does give a glimpse of what organizations are planning to do and on which approaches the Talent management actions are based.

The respondents were contacted via email. This email consisted of an introduction to the research and a hyperlink to the questionnaire. A week later, a reminder was sent to the entities that had not replied. The following week, we contacted the non-respondents by telephone to ask whether they had received the invitation, whether there were any problems and whether the right person was contacted. A few days later, these respondents were emailed once more with an invitation to participate in the

\footnotetext{
10 HR-managers have a considerable amount of autonomy in designing and implementing HR practices as long as they take into account the legislative framework regarding personnel policy aspects.
} 
survey. The participation period of the survey was closed down with 46 surveys, of which 43 were completely filled in. The response rate is thus about $77 \%$. The respondents who were contacted by telephone, revealed some of the reasons HR-managers would not participate. These contacts stated that there were, amongst others, too many surveys they had to fill in; that the leading civil servant would not give permission or that the HRfunction was vacant at the moment.

The questions of the survey varied in their form and answer possibilities. We will concisely run through the different questions. The question regarding the development stage of the talent management policy is developed as a multiple choice question. The respondents could tick one option of the five stages that were given (The organization is not receptive to a talent management policy; There is a willingness to develop a talent management policy; There are actual plans to implement a talent management policy; At the moment, the organization is implementing one or more talent management practices; The organization can look back upon an evaluation of a talent management practice ${ }^{11}$.

The question on the approach to talent management started with a short description of inclusive and exclusive talent management. The respondents had 4 options they could choose from (Inclusive talent management ${ }^{12}$; Exclusive talent management ${ }^{13}$; no idea; not applicable). It was possible to choose inclusive as well as exclusive talent management from the list to

\footnotetext{
11 The definition of talent and Talent management, as used by the working group on Talent management in the Flemish government were used. The definition of Talent management was described as follows: 'Talent Management is aimed at attracting, developing, retaining and applying talents whereby the perspective of the employee as well as the perspective of the organization are integrated.' The definition of talent was described as follows: 'Talent is the combination of doing something good and doing something you like. This results in a strong commitment to bring things to a good end.'

12 Inclusive Talent management was described as aimed at all employees. This means that every employee is part of the Talent management policy.

13 Exclusive Talent management was described as focusing on key positions in the organizations, on high potentials or high performers. Only a specific segment of the employees is part of the Talent management policy.
} 
anticipate the 'hybrid' forms of talent management that also appear in literature (Stahl et al, 2012). Furthermore, a follow-up question emerged when respondents ticked 'not applicable'. The question concentrated on which talent management approach the organizations would apply in the future (Inclusive Talent management; exclusive Talent management; no idea).

The question on the integration of HR processes in the talent management policy listed ten HR activities, of which the respondents had to state whether they were being used by the organization. The respondent had three options per HR process; used in the current situation, used in the future situation, and not applicable. Furthermore, to ensure a shared interpretation, each HR process was followed by a short description.

The results were analyzed using the statistical program SPSS (Statistical Package for the Social Sciences).

\section{> 3.2. Semi-structured in-depth interviews}

In the survey, entities that participated could indicate whether they were receptive to be contacted for further research purposes. Twenty-four entities gave their consent en were thus invited to take part in the semistructured in-depth interviews. At the moment, eighteen interviews have been conducted. The respondents of the interviews are the HR-managers, who were also responsible for filling in the survey. In this way, the results of the survey can be studied in further detail, while a more comprehensive view on the context-factors can be developed. The same limitation as with the survey research phase continues to exist: the focus in this paper is on the intended talent management policy rather than on the implemented or perceived HR-policy. 


\section{Results}

The results section is subdivided in three parts. The first part situates the centralized approach to talent management of the Flemish Government. The second part reports on the results of the survey. An overall view on the design of and approach to the talent management policies of the entities of the Flemish government is presented. In the third part, we discuss the preliminary results of the interviews. The interviews are analysed through the three dimensions that are part of the Contextually based human resource theory. Table visualizes the different research parts of the result section.

Table 1. Overview of the presented research results

\begin{tabular}{lll}
\hline Part 1 Presentation of the centralized approach to Document analysis \\
talent management of the Flemish government & Two expert-interviews \\
\hline Part 2 & $\begin{array}{l}\text { Presentation of the design and approach of talent Survey } \\
\text { management of the entities in the Flemish } \\
\text { government }\end{array}$ & $\begin{array}{l}\text { Presentation of the factors that influenced the } 19 \text { semi structured interviews } \\
\text { introduction, approach and design of the talent } \\
\text { mart } 3\end{array}$ \\
\hline
\end{tabular}

\section{> 4.1. A shared understanding of talent management in the Flemish government?}

In 2010, the Flemish government started its horizontal policy project 'Flanders in Action'. This government wide project focuses, next to several policy domains, on a key project, called 'Modern HR policy'. Within this key 
project, a subproject is developed that focuses on 'Competence and talent management'. Within this framework, a vision text on talent management within the Flemish government was developed. The goal of this vision text is to create a general language and understanding of talent management and to describe the culture that is needed to successfully implement talent management. The direction that is chosen in this document, however, cannot be imposed on the entities of the Flemish government.

Buttiens \& Hondeghem (2013) categorize the presented approach as inclusive. In addition, an object approach to talent management was also put forward (see definition below). Furthermore, it is clear from the proposed definition that organizational goals as well as individual goals (e.g. well-being) are strived for:

'Talent Management is aimed at attracting, developing, retaining and applying talents whereby the perspective of the employee as well as the perspective of the organization are integrated.'

The definition of talent was described as follows:

'Talent is the combination of doing something good and doing something you like. This results in a strong commitment to bring things to a good end.'

This approach comes close to a strength-based approach of talent management ${ }^{14}$ as described by Gallardo-Gallardo et al. (2013): 'the art of recognizing where each employee's areas of natural talent lie, and figuring out how to help each employee develop the job-specific skills and

14 Gallardo-Gallardo et al. (2013) regard the strength-based approach as being a subject approach to talent management. This does not correspond to our categorization of talent management in the Flemish government. Since the Flemish government emphasizes talents as being characteristics of their employees, we believe that the object approach is more suited. Dries (2013), however, states that the object-subject distinction is difficult to conceive 'as the characteristics of people cannot be isolated from them as a whole'. 
knowledge to turn those talents into real performance' (Buckingham \& Vosburgh, 2011)'. Moreover, this inclusive strengths approach also assures that the distribution of resources is applied in an egalitarian way (GallardoGallardo et al. 2013). This fits closely with a public sector context in which equality is considered of great importance (Garrow \& Hirsch, 2008).

With regard to the tensions of Dries (2013), it is clear that an inclusive perspective on talent management is preferred. Furthermore, on the transferrable vs. context dependent tension, the Flemish government takes a context-dependent position on the continuum as can be derived from the following quotation:

"When developing talent, the right context, support and a proper fit with individual, societal and organizational goals is necessary." (Flemish government, 2012, p. 9)

With regard to the input-output tension and the innate vs acquired tension of Dries (2013), less information is available in the vision text. Further analysis of the interviews ${ }^{15}$ can provide more information on the preferred position regarding the tensions as presented by Dries (2013).

\section{> 4.2. Approach to and design of talent management in the Flemish government}

This part of the paper presents the results of the survey ${ }^{16}$. We first take a look at the development stage in which the talent management policy of the organizations is situated. Subsequently, the approach to talent

\footnotetext{
${ }^{15}$ We will not further elaborate on this aspect in this paper.

16 The complete analysis of the results of the survey can be found in: Buttiens, D. \& Hondeghem, A. (2013). Talent Management in the Flemish Public Sector. Positioning the Talent Management approach of the Flemish Government. Revue pyramides (23). La guerre des talents aura-t-elle lieu? Travailler dans l'administration publique au XXlème siècle.
} 
management, the goals and HR-processes which are put forward in the talent management policies in the organizations are presented.

\section{> 4.2.1. Development stage of the organizations' talent management policies}

The first question concerns the development phase of the organization in their talent management policy. Five options were given, ranging from 'The organization is not receptive for a talent management policy' to 'We can look back upon an evaluation of a talent management practice'. We see in table 1 that $11 \%$ of the entities $(\mathrm{N}=46)$ does not see any opportunity to start with talent management. In contrast, almost half of the questioned organizations $(43.4 \%)$ as actively working with talent management (referring to the last three options). 
Table 2. Development stage of the organizations' talent management policies

\begin{tabular}{|c|c|c|}
\hline & Frequency & Percentage (\%) \\
\hline $\begin{array}{l}\text { The organization is not } \\
\text { receptive to a talent } \\
\text { management policy }\end{array}$ & 5 & 11 \\
\hline $\begin{array}{l}\text { There is a willingness to } \\
\text { develop a talent } \\
\text { management policy }\end{array}$ & 19 & 41 \\
\hline $\begin{array}{l}\text { There are actual plans to } \\
\text { implement a talent } \\
\text { management policy }\end{array}$ & 10 & 22 \\
\hline $\begin{array}{l}\text { At the moment, the } \\
\text { organization is } \\
\text { implementing one or more } \\
\text { talent management } \\
\text { practices }\end{array}$ & 10 & 22 \\
\hline $\begin{array}{l}\text { The organization can look } \\
\text { back upon an evaluation of } \\
\text { a talent management } \\
\text { practice }\end{array}$ & 2 & 4 \\
\hline Total & 46 & 100 \\
\hline
\end{tabular}

When we combine the number of selected HR practices per entity with the development stage of talent management (see table 2 ), a remarkable result is observed. Entities that are placed within the first two development stages nevertheless select HR practices. A feasible explanation for this contradiction can be found in the difference between a formal talent management policy and 'informally applying some principles of talent management'. Taking the conducted interviews into account, it is clear that this explanation can be confirmed. In this regard, entities with no formal talent management policy nevertheless used talent management principles in several HR-practices (e.g. career management). The presence or absence 
of a formal talent management policy, then, does not seem to inhibit the incorporation of talent management within the HR policy.

Table 3. Cross table development phase - number of selected talent management practices per entity

\begin{tabular}{|c|c|c|c|c|c|c|}
\hline & & \multicolumn{5}{|c|}{$\begin{array}{c}\text { Number of selected HR practices } \\
\text { per entity }\end{array}$} \\
\hline & & 0 & $1-4$ & $5-8$ & $9-10$ & Tota \\
\hline \multirow{6}{*}{ 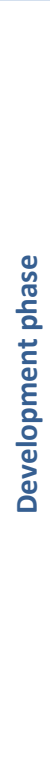 } & $\begin{array}{l}\text { The organization is not } \\
\text { receptive for a Talent } \\
\text { management policy }\end{array}$ & 1 & 3 & 1 & 0 & 5 \\
\hline & $\begin{array}{l}\text { There is a willingness to } \\
\text { develop a Talent management } \\
\text { policy }\end{array}$ & 5 & 6 & 6 & 2 & 19 \\
\hline & $\begin{array}{l}\text { There are actual plans to } \\
\text { implement a } \\
\text { management policy }\end{array}$ & 2 & 2 & 5 & 1 & 10 \\
\hline & $\begin{array}{l}\text { At the moment, the } \\
\text { organization is implementing } \\
\text { one or more Talent } \\
\text { management practices }\end{array}$ & 0 & 0 & 5 & 4 & 9 \\
\hline & $\begin{array}{l}\text { The organization can look back } \\
\text { upon an evaluation of a Talent } \\
\text { management practice }\end{array}$ & 0 & 0 & 1 & 1 & 2 \\
\hline & Total & 8 & 11 & 18 & 8 & 45 \\
\hline
\end{tabular}

\section{> 4.2.2. Approach to Talent Management}

Next to the development stage of the talent management policies, the approach to talent management was assessed. A short description of the inclusive, as well as the exclusive approach was provided. Respondents could choose for the inclusive and/or exclusive approach to talent management. More than half of the entities $\left(56 \% ; \mathrm{N}=43^{17}\right)$ state that the

\footnotetext{
${ }^{17}$ Data of three organizations are incomplete
} 
organization chooses an inclusive talent management approach. Approximately, $5 \%$ of the organizations take an exclusive approach to Talent management while two organizations of the Flemish government $(5 \%)$ combine both approaches.

Table 4. Approach to Talent management in the organizations of the Flemish government

\begin{tabular}{lcrr}
\hline & & Frequency & Percentage (\%) \\
\hline $\begin{array}{l}\text { Inclusive } \\
\text { management }\end{array}$ & Talent & 24 & 56 \\
$\begin{array}{l}\text { Exclusive } \\
\text { management }\end{array}$ & Talent & 2 & 5 \\
$\begin{array}{l}\text { Inclusive and exclusive } \\
\text { Talent management }\end{array}$ & 2 & 5 \\
No idea & 2 & 5 \\
Not Applicable & 13 & 30 \\
Total & 43 & $101^{18}$ \\
\hline
\end{tabular}

Almost $30 \%$ of the respondents selected the 'not applicable' option. When asked what approach the organization would take in the future $(N=13)$, the majority chooses the inclusive Talent management approach (62\%).

Overall, the inclusive talent management approach seems most popular in the organizations of the Flemish government. Moreover, it is interesting to see that two questioned organizations combine the inclusive and exclusive approach in their talent management policy.

\footnotetext{
${ }^{18}$ Rounding off
} 


\section{> 4.2.3. HR processes in the entities' talent management policies}

Most questions in the survey were aimed at how many and which HRpractices would be/are applied within the (future) talent management policies of the entities. We presented ten different HR practices that could be used within a talent management policy (Armstrong, 2007). Those are: recruitment and selection, attraction and retention policy, talent audit, role development, developing commitment and engagement, performance management, reward policy, training and development, career development and management development ${ }^{19}$.

The results (see table 4; $\mathrm{N}=45$ ) show that Talent management is mainly applied in processes concerning education and training (64\%); performance management (64\%) and commitment and engagement strategies (64\%). Next, role development (56\%) and career management (53\%) are selected by more than half of the respondents. The least chosen HR process is Talent audit, with 11 organizations (24\%) applying a talent audit. The reward policy seems currently $(36 \%)$ as well as in the future $(53 \%)$ the least evident choice to integrate in a Talent management policy. Since the financial reward system in the Flemish government is strictly regulated, a possible explanation could be that the lack of leeway inhibits the integration of a talent management-based approach in this practice.

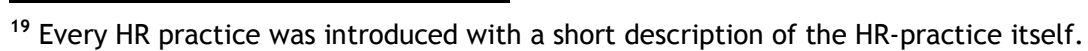


Table 5. HR processes within the Talent management policy of the questioned organizations

\begin{tabular}{|c|c|c|c|c|}
\hline & \multicolumn{2}{|c|}{ Current situation } & \multicolumn{2}{|c|}{ Future situation } \\
\hline & Frequency & $\begin{array}{r}\text { Percentage } \\
(\%)\end{array}$ & Frequency & $\begin{array}{r}\text { Percentage } \\
\text { (\%) }\end{array}$ \\
\hline $\begin{array}{l}\text { Developing commitment } \\
\text { and engagement }\end{array}$ & 29 & 64 & 36 & 80 \\
\hline $\begin{array}{l}\text { Performance } \\
\text { management }\end{array}$ & 29 & 64 & 35 & 78 \\
\hline $\begin{array}{l}\text { Training and } \\
\text { development }\end{array}$ & 29 & 64 & 37 & 82 \\
\hline Role development & 25 & 56 & 33 & 73 \\
\hline Career development & 24 & 53 & 33 & 76 \\
\hline $\begin{array}{l}\text { Management } \\
\text { development }\end{array}$ & 22 & 49 & 29 & 58 \\
\hline $\begin{array}{l}\text { Recruitment and } \\
\text { selection }\end{array}$ & 21 & 47 & 30 & 67 \\
\hline $\begin{array}{l}\text { Attraction and retention } \\
\text { policy }\end{array}$ & 20 & 44 & 34 & 76 \\
\hline Reward & 16 & 36 & 24 & 53 \\
\hline Talent audit & 11 & 24 & 26 & 58 \\
\hline
\end{tabular}

With regard to these results, a few marginal notes can be added. First, it is remarkable that every HR process that was being suggested in the survey, was selected by at least a quarter of the organizations. These results indicate that talent management is not solely applied to the HR processes that seem most popular in literature (e.g. recruitment and staffing, training and development and retention management; Thunissen et al., 2013) but are applied to a whole range of HR practices. Second, the HR practice 'talent audit' is least selected (24\%) by the respondents. This HR process can be seen as one of the starting points of a talent management policy in 
which the organization is provided an overview of the talents within the organization.

\section{> 4.2.3.1. Sub conclusion}

In summary, about $20 \%$ of the organizations is in the stage of developing a talent management policy, while a quarter of the organizations is implementing and evaluating talent management practices. It is clear that inclusive talent management is the prevailing choice in the Flemish government, as more than half of the organizations take an inclusive approach. When looking at the design of the talent management policy, the HR processes of 'education and training', 'performance management' and 'commitment and engagement strategies' were selected more often. The least popular HR process to integrate in a (future) talent management policy is the 'management of reward'. A possible explanation is that the financial reward system in the Flemish government is strictly regulated, presenting a lack of leeway that might discourage HR workers to apply talent management in this process.

After describing the approach to and design of talent management in the Flemish government, the preliminary results of the in-depth interviews will be presented along the three dimensions of the CBHRT and the concept of 'dominant coalition'. Where possible, these results will be related with the findings that emerged from the survey.

\section{> 4.3. Influencing factors on talent management in the Flemish government}

As is clear from the results of the survey, different 'designs' of talent management policy exist within the Flemish government. With regard to the approach to talent management, however, the inclusive approach is dominantly present. The interviews with HR managers of the entities 
focused on deepening the understanding of the survey results and determining which factors have brought the entities' HR policy, including talent management, to its current state. To categorize these factors, we make use of the before-mentioned Contextually based Human Resource Theory. We will subsequently discuss the organizational/administrative/cultural dimension, the social/cultural/legal dimension and the product/market/technology dimension. In addition, also the concept 'dominant coalition' will be studied since this concept gives us insight in the actors that are considered as important stakeholders for the development of an entities' talent management policy. In other words, this part of the paper attempts to list factors that influence the approach to talent management and appearance of the different designs of talent management policy. We will also categorize the factors along the sort of influence that was reached: influence on the introduction of talent management, influence on the design of talent management and influence on the approach to talent management. Furthermore, we want to stress that these factors could by no means constitute an exhaustive list. These findings are merely the product of a preliminary analysis of an on-going series of interviews.

\section{> 4.3.1. Configuration of the organization (the organizational/administrative/cultural heritage)}

While conducting the interviews, a set of factors was listed which is part of the organizational/administrative/cultural dimension. We discuss these factors subsequently.

\section{Influence on the introduction of talent management}

Capacity HR-function - The development of a talent management policy depends on the capacity of the HR function that is created in an entity. 
From the interviews, it was clear that an entity in which an HR manager could devote time to strategic thinking would formally implement talent management in the organization (this is of course only true if other necessary factors are present, e.g. support of top management). In other cases, the HR manager is mainly occupied with more operational tasks. This means that there is insufficient amount of time left to dedicate to developing or reflecting on a more strategic approach on the personnel policy of the organization in general.

Recent change in organizational structure - In 2006, a reform of the Flemish government had a considerable impact on the organizational structures of several entities. When entities were confronted with mergers, it was clear that other HR priorities were put forward. In one entity, this meant that time had to be invested in creating a common organizational culture while striving for organizational commitment for the new entity. In addition, the task of the HR manager was focused on this process which meant foremost that a reactive way of working was applied. In other entities, the merger resulted in practices that transferred people from one function to another. Some entities made use of this opportunity to apply a strength-based approach by collecting information on the preferred working area of the employees and taking this preference into account when filling in the vanacies. HR managers believed that, by following the principles of talent management, employees would be more motivated to start in a new function. As a consequence, better service and more productivity would contribute to the organizational goals.

\section{Influence on the introduction and design of talent management}

View of topmanagement - Logically, the support of the topmanagement of an entity for the principles of talent management results in a formal talent management policy. More time can be devoted to specific talent 
management initiatives like a talent audit. Moreover, a supportive culture for talent management is more likely to be created and stimulated for line management and employees.

Size of the organization - The size of the organization played a role in how talent management was implemented in the organization. In a rather small entity (less than 150 employees), it was manageable for HR managers and line management to get a view on strengths and ambitions of employees without introducing specific instruments that would list these characteristics for every employee. One important condition, however, would be that line management has the ability to recognize and acknowledge strengths of the employee while a transparent environment of mutual respect can be upheld.

Subject of the policy domain- This factor seemed to influence the introduction and application of talent management in two ways. First, the policy domain Work and Social Economy felt it had to pursue an exemplary role in their personnel policy. In practice, the entities ${ }^{20}$ fully integrated the perspective of the organization and the perspective of the employee. The strength-based approach is predominantly present. A second manner in which talent management seemed to be integrated in the personnel policy of an entity is through the correspondence with its executive functioning. The best example can be found in the Agency of Youth Welfare. This agency applies a strength-based approach when working with youngsters in special child welfare. As a consequence, the topmanagement and HR-team translate this approach to their own personnel policy: "how otherwise could our staff apply a strengths-based approach when working with youth in special welfare'. This latter factor can also be placed within the

\footnotetext{
${ }^{20}$ Two entities of this policy domain participated in the interviews.
} 
management of stakeholders ${ }^{21}$. The personnel policy of the agency is adjusted to correspond to its own executive functioning when working with clients.

\section{> 4.3.2. Product/market/technology dimension}

The product/market/technology dimension for a public sector organization is somewhat distinct from that of a private organization. Some entities are not competing in the services they deliver. The recent pressure on the budget, however, resulted in an emphasis on economic values which also influences the personnel policy in a more distinct way than before the financial crisis.

Influence on the introduction of talent management (formal/non-formal)

Change in policy mission - Along with changes in the organizational structure, a few entities experienced changes in their policy mission. In other words, certain tasks that were part of the mission of the entity were removed, while a focus on other tasks was added. As a consequence, these organizations had to assess whether the necessary competencies were still present in the organization and if this was not the case, determine a strategy to remedy the situation. However, given the recent pressure on the budget of government agencies and the statutory position of civil servants, there is little room for recruitment of needed competencies. A few entities have chosen to reorient the personnel policy to a more talent managementbased approach. In doing so, the organization tries to fully employ the strengths and competencies that are present in the organization. In choosing the talent management approach, the organization expects that people who are employed according to their strengths (defined as what they like to do

${ }^{21}$ This means that the clients of the agency, the younsters and their parents, are part of the dominant coalition that influences the personnel policy (cfr CBHRT) 
and what they are good at) make for more motivated and committed employees. However, one entity struggled with the reorientation of employees with specialist profiles. These employees were not receptive to change their tasks with regard to their knowledge area nor other functions. The same strategy is applied in entities with a client-orientation in their mission (e.g. entities who have to advise and report on specific policies of the government to external actors). One such entity, is in the process of implementing an entity-wide database in which the specific knowledge of employees is listed. However, this approach seems to fall back to a onedimensional focus on the organizational goals since knowledge areas of employees are being mapped with a limited scope. Instead of varying the tasks of an employee, the organization maps the strengths of its employees with a view to autonomously maximize its own performance.

Pressure of economic climate - The importance of economic values such as efficiency, effectiveness, speed, flexibility is often broadly referred to as 'doing more with less'. As stated above, this focus pushes organization in their search for new strategies in personnel policy and making employees as versatile as possible (see former factor for some examples of strategy). Through the application of talent management, they expect employees to stay motivated and, hence, perform better because of the fact that they are employed by their strengths.

\section{Influence on the approach to talent management}

In competition for appropriate profiles - While inclusive talent management is dominantly present in the entities of the Flemish government, some entities are inclined to use a more exclusive perspective. The starting point is the existence of vacant positions that are difficult to fill in. First, a lot of effort is spent on recruiting suitable profiles. Second, a lot of money is invested in the training and development of these employees 
since the necessary competences are not always available. Furthermore, the opportunity to develop is very important for these profiles. This can also be seen as a form of retention policy. Exclusive talent management is thus accepted when key positions are difficult to fill in. The exclusive talent management is then used to keep the employee within the organization by offering opportunities to develop. A specific policy which is based on strategic positions in the organization ${ }^{22}$, rather than on the person itself which is the case in 'a high potential or high performer policy' - seems more likely to be accepted.

\section{> 4.3.3. Social/cultural/legal dimension}

The social/cultural/legal dimension is a multifaceted concept. Values at the entity level as well as values at the general public sector level seemed to play a role when respondents were asked why they preferred an inclusive approach to talent management. It is clear that the two factors presented below do not fully cover the complete area of possible influencing factors. Further analysis should be carried out to provide a more comprehensive overview of the factors along this dimension.

\section{Influence on the approach to talent management}

Central view on talent management of the Flemish government - As stated at the start of the results section, the central view on talent management does offer a framework for entities that stimulates the approach to talent management that is presented in the vision text. This could explain the shared interpretation of talent management during the various interviews. All respondents stated that the combination of the

\footnotetext{
${ }^{22}$ Workforce differentiation does of course exist within the Flemish government. However, we want to emphasize the extra effort that is being put in this profiles because of the fact that they are difficult to fill in. The starting point is thus not the same.
} 
perspective of the organization and the perspective of the employee had been guiding principles in designing a talent management practice. Some, however, placed more emphasis on the perspective of the organization. In addition, the influence of this central view is not straightforward since entities all emphasize that the personnel policy in general and the talent management in particular have to be tuned to the specific needs and contexts of the entity itself. We can conclude that the existing shared meaning might be influenced by the central view on talent management as presented in the vision text. This shared understanding, however, was not necessarily shown to result in a similar approach to talent management since entities also developed exclusive talent management - nor in a similar design of talent management policies in the entities. In addition, we would like to point out the possibility that the underlying values that are linked to the public sector (e.g. equality) reinforce rather than diminish the tendency towards an inclusive approach to talent management.

\section{Influence on the approach and design of talent management}

Regulatory rules regarding personnel management in the Flemish government - The legislative framework concerning the statute of civil servants starts from a standardized view on HRM. In practice, talent management focuses on the ambitions and wishes of the individual. Most HR managers do not consider this custom-tailored approach to be opposed to the equality value which is at the core of the legislative rules. Every individual gets the same opportunity to participate in the talent management practices. This means that not everyone is treated in the same way but the starting point of receiving chances is equal.

In table 6 an overview of the above-mentioned factors is presented. 
Table 6. Overview of dimensions that influenced the talent management policy

\begin{tabular}{|c|c|c|c|}
\hline & $\begin{array}{l}\text { Influence on } \\
\text { Introduction of TM }\end{array}$ & $\begin{array}{l}\text { Influence } \\
\text { on } \\
\text { approach of } \\
\text { TM }\end{array}$ & $\begin{array}{l}\text { Influence } \\
\text { on design } \\
\text { of TM }\end{array}$ \\
\hline \multicolumn{4}{|l|}{ Configuration of the organization } \\
\hline Capacity HR-function & $x$ & & \\
\hline $\begin{array}{l}\text { Recent change in } \\
\text { organizational structure }\end{array}$ & $x$ & & \\
\hline View of topmanagement & $x$ & & $x$ \\
\hline Size of the organization & $x$ & & $x$ \\
\hline Subject of the policy domain & $x$ & $x$ & $x$ \\
\hline \multicolumn{4}{|l|}{ Product/market/technology dimension } \\
\hline Change in policy mission & $x$ & & \\
\hline Pressure of economic climate & $x$ & $x$ & \\
\hline $\begin{array}{l}\text { In competition for appropriate } \\
\text { profiles }\end{array}$ & & $x$ & \\
\hline \multicolumn{4}{|l|}{ Social/cultural/legal dimension } \\
\hline $\begin{array}{l}\text { Central view on talent } \\
\text { management of the Flemish } \\
\text { government }\end{array}$ & & $x$ & \\
\hline $\begin{array}{l}\text { Regulatory rules regarding } \\
\text { personnel management in the } \\
\text { Flemish government }\end{array}$ & & $x$ & $x$ \\
\hline
\end{tabular}




\section{> 4.3.4. Dominant coalition}

The dominant coalition plays an important role in the constitution of an HR policy of an entity. The actors within this dominant coalition decide how the HR-policy of an entity will be configured. The choice for a certain type of HR policy is, however, bounded when entities take into account the abovementioned dimensions. Within the interviews, HR managers were asked which parties they distinguished in the process of deciding on and developing an HR policy of their entity. Their answers give us some insight in to the thought given to and the relative weight of these actors within the dominant coalition.

The actors that the HR managers defined were on the level of the top management, line management, employees, politics (minister and cabinet), customers and entities sharing an interdependent relation with their own. The HR managers started their enumeration with the top management level. Within all entities, this was regarded as a self-evident actor within the HR policy.

Subsequently, to incorporate the interests of the line management and employees, some entities made use of surveys. Within the employee surveys, attention was paid to job satisfaction, organisational commitment, relationship with the line manager,... When critical points appeared in the results, actions within the HR policy were undertaken to counter them.

Another actor that is taken into account structurally are the trade unions. Consultation of the trade unions is mandatory when an entity wants to adapt its HR policy. With regard to talent management, it can be concluded that the position of trade unions differed significantly between entities. Further research is needed to elaborate upon this finding.

The following actors were not listed in every interview. When mentioned, however, these actors seemed to have a considerable influence on the development of the HR policy. 
A double role can be ascribed to political actors. On the one hand, we distinguish the influence of a minister and his cabinet on the HR-policy within their assigned policy domain. They are considered as an important actor within the constellation of the dominant coalition. On the other hand, however, we can also discern a broader political sphere which is an expression of the zeitgeist of the current socio-political situation. Norms and values that determine the concepts of fairness and legitimacy are also voiced throughout the political system. In this manner, the current political constellation is also part of the social/cultural/legal dimension.

Some entities also mentioned the customer as being part of a dominant coalition. These entities can be considered to be more client-oriented than others. To follow up the quality of service, customer surveys are carried out. The results of these surveys are used to adapt the HR policy. In one case, it was clear from the results that other skills were needed to maintain the quality of service. Initiatives were then undertaken with regard to training and development.

Another actor that was listed, were entities that shared an interdependent relationship with one's own. The HR policies of those entities were geared towards one another because they had been developed and implemented by one centralized HR-department or because they functioned interdependently.

\section{Conclusion}

While talent management as a field of study is evolving from its infancy to adolescence, Thunissen et al. (2013) conclude that literature concerning talent management is biased towards a managerialist and unitarist view. Despite a conceived lack of empirical research, a dominant focus on (multinational) organizations in a for-profit context can be observed 
(Collings \& Mellahi, 2009; Thunissen et al, 2013). This paper tries to broaden the scope by looking at talent management in a public sector context. A study of talent management implementations within entities of the Flemish government was presented through survey results. In addition, through the use of the Contextually based Human Resource Theory, a broader view on performance could be incorporated since the shareholder orientation of a managerialist approach was complemented with individual as well as societal goals. The CBHRT starts out from an organization that is embedded in its institutional context and takes into account the organizational and strategic fit. Factors of influence were categorized along the three dimensions of the CBHRT: the product/market/technology dimension, the social/cultural/legal dimension and the configuration of the organization (organizational/administrative/cultural heritage).

The survey results, which depicted the approach to and design of the talent management policies in the entities of the Flemish government lead us to conclude that the inclusive approach to talent management is the prevalent approach. More specifically, as highlighted by the general view on talent management of the Flemish government and the interviews at entity-level, a strength-based approach was chosen in almost all cases. The strengthbased approach uses both the perspective of the employer as well as that of the employee as a starting point for the implementation of talent management policies.

A preliminary analysis of the in-depth interviews that are presently being conducted, reveals a set of factors that influence the introduction, approach and design of talent management in the entities of the Flemish government. Summarizing, it can be stated that the majority of the factors highlight existing needs of entities (e.g. adaptation to changes in the policy mission, organizational structure, growing importance of economic viability) that forces them to adapt their personnel policy. The needs of the 
organization can dominantly be situated in the dimensions that focus on the product/market/technology dimension and the configuration of the organization. The introduction of talent management, as defined by the majority of the entities, offers the possibility to take into account the needs of the employee while still being able to pursue organizational goals. This approach to talent management is primarily influenced by the social/cultural/legal dimension. Even when an exclusive approach is taken, often as a result of fierce competition in the search for specific profiles, respondents stressed the need for an inclusive policy because of a felt obligation to stay in accordance with the organizational culture. The exclusive approach could be observed to limit itself to the management of specific key positions of the organization and avoids the focus on persons as high potentials or high performers. With regard to the proposed factors and the dominant coalition, however, we want to stress that deeper analysis is needed to expand the list presented and refine it further.

One of the limitations in this paper is that we only consulted the HR managers within each of the entities in the Flemish government. The perception of the employees on the different practices is not included in the scope of this research phase. We opted for this approach because our main goal was to create an overall view on the approach to and design of talent management policies in the Flemish government. HR managers are in the most advantageous position to provide information on this subject. Furthermore, we only consulted one respondent per organization for the survey as well as for the interviews. In this way, it was possible to ask respondents to elaborate on the answers that were provided in the survey. In the following stages of research, specific cases will be studied. This means that more interviews will be conducted with a range of stakeholders that could not be incorporated in this research phase. Furthermore, the focus on a specific case will offer the possibility to describe in a more 
detailed way the elements that play a part in developing a talent management policy.

\section{References}

Armstrong, M. (2007). A handbook of human resource management practice. London: Kogan Page.

Boselie, P. (2010). Strategic human resource management. A balanced approach. Birkshire: MCGram-Hill Higher Education.

Boselie, P., Brewster, C. \& Paauwe, J. (2009). In search of balance. Managing the dualities of HRM: An overview of the issues. Personnel Review, 38(5), pp. 461-471

Bothner, M.S., Podolny, J.M. \& Smith, E.B.(2011). Organizing contest for status: the Matheweffect vs. the mark-effect. Management Science, 57(3), pp. 439-457.

Buttiens, D. \& Hondeghem, A. (2013). Talent Management in the Flemish Public Sector. Positioning the Talent Management approach of the Flemish Government. Revue pyramides (23). La guerre des talents aura-t-elle lieu ? Travailler dans l'administration publique au XXlème siècle.

Devine, M. \& Powell, M. (2008). Talentmanagement in the public sector. $360^{\circ}$, The Ashridge Journal, autumn(2008), pp. 1-6.

Dries, N., The psychology of talent management: a review and research agenda, Human Resource Management Review (2013), http://dx.doi.org/10.1016/j.HRMR.2013.05.001

Collings, D.G. \& Mellahi, K. (2009). Strategic Talentmanagement: A review and research agenda. Human Resource Management Review, 19(4), pp. 304-313. 
Gallardo-Gallardo, E., at al., What is the meaning of 'talent' in teh world of work? Human Resource Management Review (2013), http://dx.doi.org/10.1016/J.HRMR.2013.05.002

Garrow, V. \& Hirsh, W. (2008). Talentmanagement: Issues of focus and fit. Public Personnel Management, 37(4), pp. 389-402.

Harris, L. \& Foster, C. (2010). Aligning talent management with approaches to equality and diversity. Chalenges for UK public sector managers. Equality, diversity and inclusion: an international journal. 29, 5, 422-435.

Knies, E. (2012). Meer waarde voor en door medewerkers. Een longitudinale studie naar de antecedenten en effecten van peoplemanagement. Amersfoort: Wilco.

Lewis, R.E. \& Heckman, R.J. (2006). Talentmanagement: a critical review. Human resource management review. 16, pp. 139-154.

Paauwe, J. (2004). HRM and performance: achieving long-term viability. Oxford: Oxford University Press.

Thunissen, M. , Boselie, P. \& Fruytier, G. (2013) A review of talent management: 'infancey or adolsecence?', The international Journal of Human Resource Management, 24:9, pp. 1744-1761.

Thunissen, M. , et al. (2013). Talent management and the relevance of context: Towards a pluralistic approach, Human resource management review (2013), http://dx.DOI.ORG/10.1016/j.HRMR.2013.05.004

Vaiman, V. \& Collings, D. G. (2013) Talent management: advancing the fiels, The international Journal of Human Resource Management, 24:9, pp. 1737-1743.

Vlaams Overheid (2012). Visienota. Naar een talentenbeleid binnen de Vlaamse Overheid. Brussel: z.u. 